\title{
Is Community Informatics good for communities? Questions confronting an emerging field
}

\author{
Randy Stoecker \\ University of Toledo $<$ randy@,comm-org.utoledo.edu $>$
}

\begin{abstract}
This paper addresses a number of questions confronting the emerging field of community informatics. First, is it a field of study or a field of practice? Second, is the focus of community informatics on communities, information, or technology? Third, does community informatics serve elites, academics, community workers, or community workers? The paper moves from these questions to develop an empowerment model for community informations, emphasizing a community development approach combined with an information focus and a participatory process. It concludes with the question of whether community informatics should strive to be a supporting field rather than develop as an independent arena of study or practice.
\end{abstract}

\section{Introduction}

I have been doing Community Informatics work for nearly a decade now, ever since we did a needs analysis of the community organizations in Ohio's largest cities in 1996 and then built a local community technology intermediary called CATNeT. I am now teaching courses in Social Informatics and Community Informatics. I build my own computers, manage two servers, and work with a number of different Community Information technology projects. But I must admit that thinking of myself as someone who does Community Informatics has always left me feeling vaguely uncomfortable. Perhaps it is because, in contrast to the other fields I mess around in-community organizing, community development, and community-based research - Community Informatics has always felt like it was separate.

It has always felt separate to me because, unlike those other fields, the answer to the social problems of the day are already implied in Community Informatics. In some way, shape, or form, the answers always have to do with computers. That is not the case in community organizing, community development, and community-based research, whose "toolboxes" include a wide range of tools, and even computers sometimes. A community organizer friend of mine is fond of the saying that "if the only tool in your toolbox is a hammer, all problems look like nails." And so it may be with the emerging field of Community Informatics. This emerging field, with its concentration on the computer as the central tool, is in danger of seeing all problems as technological.

It is interesting how many of us in this emerging field of Community Informatics seem to share a similar sense of unease. Bill Pitkin's (2001) provocative essay, "Community Informatics, Hope or Hype?" 
expresses the unease as overselling technology as a solution. One of Doug Schuler's favorite T-shirts says "Question Technology." It is unfair to charge this new field with blindly promoting technology, as it is clear so many of us are worried about just that. And yet something is missing for many of us. I write this essay to better understand the crucial questions the field needs to face in order to move forward. And it seems the best place to start is with trying to define the field itself.

\section{What is Community Informatics?}

While the practice of using information and communication technology to serve communities has been around for some time, the definition of that practice and the study of its effects is still emerging as a field. So young is this emerging field that the Community Informatics Research Network was founded only in the fall of 2003. It was only in 2000 that the first important hard copy volume of work on Community Informatics was published (Gurstein, 2000).

Centers devoted to research and practice in Community Informatics are also quite young. One of the oldest, the Community Informatics Research and Applications Unit (CIRA) at the University of Teesside, was established only in 1996 (CIRA, n.d.). Other centers devoted explicitly to Community Informatics, such as the Center for Community Networking Research at Monash University, and the Community Informatics Research Group at the New Jersey Institute of Technology, are even younger.

So it should be expected that the definition of the field should be in some flux as well. The inventor of the term, Michael Gurstein (2003), describes Community Informatics (perhaps unintentionally) as having two forms. On the one hand, "Community Informatics (CI) is the application of information and communications technologies (ICTs) to enable community processes and the achievement of community objectives." On the other hand " $\mathrm{CI}$ is the terminology that is coming to be used to describe the academic discipline and practice for systematically approaching Information Systems from a 'community' perspective." (Bieber et al. 2002). There is a desire to bring together these two perspectives, but as of yet only the Community Informatics and Information Systems: Mapping the Sector project (n.d.) has attempted to define the field comprehensively. And that project is only in its earliest stages.

So, given that the field is characterized by both a practice approach and a scholarly approach, it seems useful to better understand these definitions separately before attempting to combine them.

\section{A field of study}

As a field of study, Community Informatics is woefully underdeveloped. Indeed, as Tom Denison and colleagues (2003) have concluded, "an adequate theoretical analysis of the character of Community Informatics as a recognizable form of social institution or practice has not occurred." It takes more than a theoretical analysis to constitute a stable field of study, however. For Community Informatics to be a field of study, it must have an agreed upon set of core questions, an array of methodological techniques and practices, and a set of theoretical approaches.

Is there a set of core questions? Indeed, a Google search of "Community Informatics" with "core questions" in December of 2004 turns up exactly four hits, none of which address the issue of what the core questions of Community Informatics should be. What we find instead of core questions are a wide array of discipline-based researchers writing about and conducting research on the digital divide, NGOs and NPOs, interpersonal networks, virtual communities, and all manner of other topics related to communities and technology. To date, no one has taken that writing and research and attempted to distill a set of common questions from it. This in itself would be worthy of a grant to determine what the boundaries of the field might be and what questions are being addressed across the blossoming Community Informatics literature.

There is also not a body of theory that we can point to as constituting a field of study called Community Informatics, as we have already seen. Indeed, even if we consider Community Informatics as a subfield of the broader field of Social Informatics (Kling, 1999), we find less than we would hope. Manuel Castells' $(1996 ; 1997 ; 1998)$ massive three-volume work has attempted to build some definable body of theory around information technology in general, but the very massiveness of the work makes it difficult to apply in community settings. Much of the writing and research we do find is driven more by anecdotal reports and story-telling than by the use of theory (Pitkin, 2001; Denison et al., 2003).

Finally, it is also difficult to find an agreed-upon set of methodological techniques and practices. There are far more anecdotal reports than the average academic field would be comfortable with, using a 
case study methodology that many academic disciplines would consider lacking in rigor. The opportunities for comparative research, linking the many analyses of individual community computing centers, have not been realized. And, of course, the development of a kitbox of research techniques is hampered by the lack of core questions and theory.

What we have then, is a field of study that looks very much like the Internet itself. There are a variety of researchers doing work that they individually define as falling under the general rubric of Community Informatics, and hoping to recruit others. The field of study, then, is very much in its infancy. So much in its infancy is it that the Sociology and Anthropology faculty at the University of Toledo refused to make a hire in even the broader area of Social Informatics in 2003.

It is another question altogether whether it matters that Community Informatics is underdeveloped as a field of study. In this post-disciplinary, inter-disciplinary, non-disciplinary age, things like core questions, paradigmatic theories, and common methods can seem anachronistic. So it is important to ask whether we want Community Informatics to be a disciplinary field of study or only a topical area of inquiry. If the former, we have much to do. If the latter, we may have already done too much, particularly because so much of the emphasis in Community Informatics is on applied work.

\section{A field of practice}

Community Informatics as a field of practice is much more developed. Indeed, many of those now working in Community Informatics as a field of study began by working in it as a field of practice. And they have brought those interests with them.

But even the practice of Community Informatics diverges within itself. One division is between the development of community information systems-more or less the community-based version of management information systems (Bieber, 2002) used in the government and corporate sectors - and the development of community networks, which begins to move more in the direction of focusing on building the knowledge and information capacity of community members, often leading to the creation of electronic rather than face-to-face relationships (Russian Communities Online, n.d.). Another set of divisions is between Community Informatics projects that focus on enhancing democracy, developing social capital, empowering individuals, building community, and developing local economies (O'Neil, 2001). These are significantly different areas, requiring dramatically different kinds of expertise outside of information technology.

In any developed field of practice you will also find statements of ethics and standards of practice. There have been some attempts to draw out the ethical issues from specific application contexts such as Northern Ireland, but there has been no general set of ethics developed for Community Informatics. Likewise, there are no agreed upon standards of practice, though some attempt to develop such standards. William McIver (n.d.), for example, has proposed standards of practice that emphasize accessibility, universal design, and participatory design. It's not fair to say that an ethical vacuum exists in Community Informatics, since practitioners bring their standards of practice from the more established disciplines and professions from which they come. And one of the reasons so many of us have been drawn to this emerging field of Community Informatics is because we see the need for integrating technology with social justice work. But the lack of a codified set of ethics and practice standards is a sign of the underdevelopment of Community Informatics as a field of practice.

\section{An integrated field?}

Because of the potential disjuncture between Community Informatics as a field of study and Community Informatics as a field of practice, we also need to ask what the relationship between the two should be. Will it be like the professional fields of public health, social work, public administration, and others where scholarship and practice are interwoven? Or will practice and scholarship keep each other at arm's length? And if practice and scholarship are to be integrated, through what forms will that integration occur?

Here there are some interesting possibilities. Community Informatics is coming of age in the midst of a revolution in the way we conduct research. The exploding popularity of participation- and actionoriented forms of research such as community-based research (Strand et al., 2003) is occurring at the same time as the rise of Community Informatics as a field. The integration of practice and scholarship occurring 
in community-based research is already popular among many in Community Informatics at least in part because of the participatory design model being used in so many Community Informatics projects (Day, 2000; Campbell and Eubanks, n.d.; Gurstein, 2003b).

A participatory and action oriented approach to the integration of research and application will not resolve the question of what the field itself should focus on, however. And the lack of a defined theoretical perspective may remain the greatest weakness, particularly since even community-based research can be conducted from incompatible theoretical perspectives.

\section{A distraction?}

Finally, heretical as it may seem, we must ask whether this field is a distraction. And I wish to devote the rest of the paper to this possibility. If the goal, ultimately, is to develop strong communities, does creating a field devoted only to the application of information technology in community settings really serve that goal? The fields of Social Work, Community Development, and Public Health have, for some time now, been focusing much more comprehensively on building strong communities and building up weak ones. Should we assume that information and communication technology is such a central part of that process that it deserves a place as a separate field?

Or, are our efforts better placed in bringing Community Informatics into those other fields- to make sure that the community goals drive the technology goals rather than vice versa? In a small rural community, for example, does the technology plan need to be integrated with the sustainable agricultural plan, and the local business development plan, and the family support system plan, and the regional medical care plan, and all the other plans that are needed to lift up disinvested rural communities? And does that make the technology plan just a member of the supporting cast under the rubric of broader fields of practice and study?

To me, the question of whether focusing on Community Informatics as a field is a distraction is centrally important. Because it may be that our fascination with the technology is distracting us from our concern for the community. I felt this tension in the work I did with Larry Stillman surveying the neighborhood houses in Melbourne's western region where it became clear how interwoven the information technology issues were with broader and more fundamental community development infrastructure issues. In a similar recent project in Toledo, we focused our efforts on emphasizing the information issues faced by nonprofit groups, rather than the technology issues, allowing us to see that in many cases the groups lacked information that could not be obtained through simply offering more technology, but instead required resources to support original data gathering.

Dealing with this issue requires moving onto the next question.

\section{What is Community Informatics for?}

In asking what is Community Informatics for, I am asking what is its purpose? Is it to build up communities, or develop information, or provide access to technology? The easy answer, of course, is all three. But that's the easy answer, not the simple one. For these purposes are neither clear nor even necessarily compatible. And to understand the potential problems in the relationships between these concepts, we need to first spend some time defining these three building blocks of Community Informatics.

\section{Community}

Defining community is the toughy, and the one we often get hung up on. People often groan when I insist on defining what community is. But if we are trying to build community, it seems to me we must define it. Carefully. And a careful definition has not developed within the emerging field of Community Informatics.

Michael Gurstein originally used the concept to emphasize place-based communities (Gurstein, 2003), but has since expanded the concept to include on-line communities (Bieber et al., 2002). But what a community is, beyond some group of people having a sense of unity, remains out of reach. In addition, within Community Informatics, the concept has not expanded to include identity communities (Boyte, 1984) such as ethnic communities, gay and lesbian communities, and others who are often scattered beyond a single neighborhood but share free spaces (Evans and Boyte, 1986) such as bookstores, cafes, churches, and other places where they gather face to face. What we actually have, then, is a continuum from strictly 
place-based communities (Lyon, 1987) where people interact predominantly in a face-to-face manner, to strictly virtual communities where people interact only through electronic means. Importantly, in this continuum, it is the virtual community where the sense of unity - at least if we take unity to mean some form of ideological consensus - is most important. For neighborhood and small town communities often are characterized by ideological diversity, even when their members still support and defend one another. Our use of "unity" needs to be much deeper and nuanced, to notice both diversity and consensus.

My definition of community draws on both spatial and identity characteristics, and follows the work of John Logan and Harvey Molotch (1987). In their definition, a community provides: "a focal point in which one's daily needs are satisfied;" informal support networks; "a sense of physical and psychic security;" an identity; "agglomeration benefits" (unique goods and services provided because enough demand has developed in one place); and a shared ethnicity. This is an ideal type definition because it outlines the attributes of the most fully functioning community. In practical terms, this ideal type community is most often a neighborhood with a grocery store, hardware store, pharmacy, and park. It is a place where people feel physically safe, and experience a sense of current and future security. And culture is extremely important. There are many strong urban ethnic enclaves and alternative communities that approach this definition in various ways (Abrahamson, 1996). But there are also strong communities whose identity emphasizes diversity, such as the Dudley Street neighborhood in Boston (Medoff and Sklar, 1994).

If the purpose of Community Informatics is to build community, then we must take this definition into account. Can technology help create a focal point where people satisfy their daily needs? Can technology help provide informal support networks? Can technology provide a sense of security? Can it help develop an identity? Can it help provide unique goods and services? Most importantly, can it do any of those things by itself?

\section{Information}

Information is often confused with technology, in the sense that once you have the technology it is assumed you will get the information. Nothing could be further than the truth. When the United States Secretary of State Colin Powell went to the United Nations, he was armed with high tech satellite photographs, intercepted communications, and a variety of other high-tech forms of "evidence" to assert that Iraq had enormous stockpiles of horrifically deadly weapons. All that technology, and thousands of lost lives later we find out there was no information. In this case, and in the case of most of our e-mail inboxes which are now so chock-full of offensively titled spam that we are becoming phobic about clicking that "check mail" button, the technology in fact negates the flow of good information. VICNET-the famous community network serving the State of Victoria in Australia- has now locked its e-mail system so tightly that it refuses increasing amounts of legitimate e-mail.

It is also distressing to me that the organizations out there dedicated to helping non-governmental organizations (NGOs) build their information capacity, such as NPower and Making the Net Work, can provide all manner of tools to assess those groups' technology needs, but there is nothing to help them determine their information needs. If our emphasis is on information, then why do all of our tools emphasize technology? On the other hand, the information needs assessment projects out there often seem separate from ICT applications (see for example Michel et al., 2002). The recent Toledo project mentioned above is attempting to bridge the gap between information assessment and technology assessment by looking first at the research and data needs and practices of Toledo's nonprofit organizations, avoiding almost entirely the question of technology. Now that we have discovered what the information needs are, we are planning ways to help meet those needs, including possible information technology applications.

All of this, however, begs the question of what constitutes information. Information is much more difficult to define than community. But, like community, we can define what is ideal information. Perhaps the most important standard for information is that it be useful — when acted upon, it produces the predicted effect. What is useful will vary tremendously from situation to situation, and that is exactly why information needs assessments are so important. In many ways, it is the definition of information that will lead to prescriptions for appropriate technology.

\section{Technology}


Technology is too often the place where we start, when it should be where we end up. Too many Community Informatics practitioners and proponents act as if it is the technology that will build community, seeing technology as an independent rather than dependent variable (Pitkin, 2001).

It is in determining the appropriate role of technology that we can see most clearly the importance of social theory. Old school geography used to argue that the driving variables in urban society were population, organization, environment, and technology - the POET formulation (Duncan, 1959; 1961; Hawley, 1973). All four were seen as relatively independent influences on the shape of urban space and the dynamics of social life. But in the 1970s and 1980s a group of critical geographers, including David Harvey (1985), began arguing that it was the dynamics of material production and its resultant class structure that determined the shape of the population, the form of social organization, the type of environment, and the character of technology. They argued, for example, that suburbanization in the United States was not the result of the creation of the car, but the result of corporate decisions that moved manufacturing out of central cities and government decisions that subsidized suburban rather than central city housing development (Gottdiener and Feagin, 1988).

Neither computers nor guns are neutral pieces of technology. The design of technology is being driven by the demands of the rich for profit, not by the demands of the poor for access. With only a little informal training, and access to some informal technical assistance, community members can build their own mail order computer for a few hundred dollars. But they are still buying branded pre-built computers with proprietary components for two to four times that much. Community computing centers are accepting grants from Microsoft to install proprietary software requiring high levels of skill in understanding software-based licensing restrictions and anti-virus defense, rather than free, stable, and easily defended Linux systems. The computer end-user, consequently, becomes both de-skilled and dependent. What would a Community Informatics project look like that emphasized easily replaceable generic hardware, free and open source software, and a community relationship-building process that embraced those two ideas?

Part of the problem is that, in contrast to community, which has been so misused that no one wants to try and carefully define it, and information, which has so many varying definitions that it is unclear which is the right one, Information and Communication Technologies, or ICTs, are easy to define. We're talking here hardware and software - phones, radios, televisions, cameras, computers, etc. All nice, concrete, easy to measure stuff. It's so much easier to concentrate on the pieces that we can have some confidence in understanding.

\section{ciT, cIt, or Cit?}

Two years ago, when I was in Australia, I began thinking about an article from the community development literature on community economic development (CED) (Boothroyd and Davis, 1993). Their play on the acronym CED, capitalizing each letter in turn to show how the practice would look different if you made one of the concepts more important than the others, got me thinking about the interplay of community information technology. What happens if community is the most important concept, or if information is, or if technology is?

Since we have not developed standards for what would constitute a "community" approach to Community Informatics, compared to an "information" approach or a "technology" approach, we do not know what happens under the three conditions. But we can imagine that the consequences might vary significantly (Stoecker, 2002). A community approach might emphasize building relationships among community members and a collective sense of community power, and then explore ways that ICTs can be one of the strategies for supporting that process. An information approach might look at the information needs of a community, and various ways, including ICTs, that those needs might be met, risking the possibility that the information development will go to waste if the community is not strong enough to use it. A technology approach might focus on introducing new technologies into a community, risking the possibility that it could disrupt rather than build community relationships and distract community members from information activities requiring other forms of technology, such as good footwear to pound the pavement and knock on the doors of their neighbors.

Who does Community Informatics serve? 
Those of us in this emerging field of Community Informatics focus on serving historically excluded communities. But we have already seen that Community Informatics as a field of study lacks a coherent core, and Community Informatics as a field of practice lacks explicit standards. Our definition of community is weak, and information needs are often considered after technological desires. Given these issues, it seems fair to wonder whether we are effectively serving the communities we target, or perhaps unwittingly expending our energies for the benefit of the more privileged or even the enemy.

\section{Elites}

It might seem odd to consider that Community Informatics would serve elites. And yet, let us consider the kinds of projects carried out under the rubric of Community Informatics. The average telecenter, as Scott Robinson (n.d.) points out, is a place where youth become engaged in mass consumption rather than a place where community power is built. And if we look at the education programs conducted through such centers, they are focused on job training - integrating people into the lower rungs of the capitalist economy rather than helping them to question it (Penuel, 2001; Youth Development Trust for the IDRC, 2003). The result is a low-wage, compliant workforce that does more for stockholders than members of excluded communities.

This focus on training individuals in ICTs is hoped to develop social capital, which has been defined in various ways, but mostly focuses on building individual capacities and linking those capacities across a community for the purpose of economic development. Social capital has been explicitly defined as such to focus on its role in economic production. But, when you take social relationships and deploy them as economic development capital, you turn them into exchange relationships governed by contracts rather than by friendships (Stoecker, 2004). So once again, we see the influences of a capitalist economy directing the shape of the community's development rather than the community establishing an independent, empowered, sustainable development path.

The next step after individual training and social capital formation is a community-focused ICT strategy such as the community portal. Community portals become one-stop shops for community commerce, and are increasingly promoted as a form of community economic development (Creating and Sustaining Online Communities, 2000). In this case the entire community, rather than just its individuals, become integrated into the capitalist economy. And the portal sector, if we can call it that, is already being dominated by large corporations (Penuel, 2001).

Market-oriented thinking regularly works its way into the overall field of Community Informatics. There is often an explicit comparison made between the community information systems version of Community Informatics, and Management Information Systems, based on a corporate model, with a corresponding concern that CI has not become as marketable as MIS (Bieber et al., 2002).

The most cynical analysis, then, would argue that Community Informatics, through an emphasis on job training, social capital, and community commerce portals, serves elites in three ways. First, it quiets discontent by integrating poor people into the system, making them slightly less marginal, and reducing their energy to organize against the system (Cloward and Piven, 1993). Second, it encourages communities to give up their unique characteristics to appeal to mass markets, reducing community-based resistance to global capitalism. I remember a conference on the west coast of Australia a few years ago where community folks expressed concerns that community portals would force them to market themselves according to rules set by outsiders, disrupting the unique cottage economy they were trying so hard to preserve. Third, by implication, the model on which these activities are based make it the individual's, and then the community's, responsibility to pick themselves by the bootstraps and fit in. When ICTs are provided for people, it is expected people will make use of them to get jobs and develop their economies, not to try and change the system. And if they don't better themselves, it is their own fault, not the fault of a political economic system organized by and for elites. This is the classic victim-blaming switcheroo, where the poor are blamed for their poverty even when it is clear that the economy cannot provide adequate jobs, equitable education, and comparable justice (Ryan, 1976).

\section{Academics}

How might Community Informatics benefit academics? Well, many of us are building reputations and even careers out of Community Informatics. We get access to rich data, research projects, and applied projects. Yes, we all like to complain (me included) about the sacrifices we make, since our skills could 
easily get double the salary in the corporate market. But we still have pretty privileged lifestyles, jetting around the globe to meet with other experts in this emerging field, and writing journal articles and books for each other.

And the more we academics talk to each other, the more we feel like we know something, and the more we try and take leadership in Community Informatics projects. While the participatory design emphasis in Community Informatics is quite strong, it is still quite interesting how many telecentres, or community technology centers as we call them in the United States, look so much the same. Community participation is promoted, but only rarely practiced in ways that can make us all look proud. When was the last time anyone had even 100 community people turn out to plan a telecenter? It's easy to say, "well, they're not really interested" when the reality is that we professionals are simply not good at getting people to a meeting. And besides, we (erroneously) believe that we know what they need anyway.

We contribute to Community Informatics as an exclusive domain that makes it hard for community people to want to participate. Look at what we've called the field, for example. Community Informatics? What does that mean to someone whose basic concern is making their paycheck last through the month? We publish our work in the terribly inaccessible PDF format, making it extremely difficult for the people we most want to help - people too poor to afford any computer or a fast enough computer, and people with sight disabilities - to even access the things we write. And then let's not even talk about the way we write.

\section{Community Workers}

The poor community workers are often second rung players in Community Informatics. Kind of like middle management, they get the blame when the telecentres designed by the professionals don't work, without the power to do anything about it. Especially since many of them lack the technology skills needed to take organize Community Informatics projects themselves, they become dependent on outsider technical expertise. And the integration of technology expertise with community development expertise is still rarely achieved.

It is less clear how Community Informatics serves this group. In fact, as Larry Stillman and I found in our work with the Neighbourhood house workers in Australia's western suburbs, technology may actually be doing as much harm as good. At least some of the technology applications used by community workers is designed to serve elites, maintaining databases on clients and programs to inform government and funder elites rather than to directly serve clients.

Community workers, next to community members, are the people that Community Informatics most needs to serve, as they are the intermediaries to the community itself. But how Community Informatics should serve them is still unclear, as most of our efforts are still focused on developing the technology rather than the information or the community. How to remedy this situation is also compounded by a split within the field of community work itself between those community workers who have an individual clinical focus and those who have a community advocacy focus, which we will address below.

\section{Community Members}

This is the group with which we really are most concerned. But it is also the group about which we understand the least, particularly in a Community Informatics context. The evidence of whether CI really helps communities is at best speculative and anecdotal (Pitkin, 2001). We know that it helps individual community members. But we don't know whether those individuals would have succeeded even without such projects. And our inability to show such impacts is already hindering the funding of Community Informatics projects.

We can point to particular efforts that pay off, however. The social movement wing of Community Informatics has the most to show for its efforts. It has developed models serving the anti-globalization movement that have the desired effect of inhibiting global capital from becoming even more powerful than it is already. It has helped force the Mexican government to negotiate in good faith with the Zapatistas in Chiapas. It has built a powerful political force called MoveOn.Org in the United States (Stoecker, 2002b).

But at the level of the local community, we are still hard pressed to show impact beyond the level of individuals. This is partly a research methodology problem. Showing the relationship between a Community Informatics project and crime reduction, or community relationships, or neighboring patterns, 
is extremely difficult. As we will see below, that may also be a result of our emphasizing technology as the main question in Community Informatics.

\section{Toward An Empowerment Model of Community Informatics}

As worrisome as all these questions are, those of us working in the emerging field of Community Informatics are not yet ready to give up on it. Neither, however, should our philosophy be "damn the torpedoes, full speed ahead." We have the opportunity to make early course corrections, and we should make the most of that opportunity.

Our goal, I believe, is for Community Informatics to contribute to empowered communitiescommunities that are politically, culturally, and economically strong enough to negotiate agreements with corporations and higher level governments that bring them more benefits than costs. That is a tall order, and it is quite clear that Community Informatics can't accomplish those goals by itself. So those of us in this emerging field need to think bigger, considering how Community Informatics fits into an overall community development strategy, using a participatory process, a project-based research approach, and an information focus.

\section{Community Development Strategy}

The model has to begin with community. While the call has been made for a linkage between community development and Community Informatics, that linkage has not been made in any explicit sense (Bieber et al., 2002). And that is our first task.

Community development, as it is used outside of the United States, is a comprehensive strategy including a wide range of activities from business and housing development, to various forms of community organizing, to service delivery. It often uses a systems approach, considering the entire community - its politics, economics, demographics, resource base, and other characteristics - in creating a sustainable, self-sufficient, empowered community (Cook, 1999; Tamas, Whitehorse, and Almonte, 2000). In the United States, the term is mostly limited to business and housing development, though there is continuous pressure to expand the definition. Dave Beckwith (1997) explicitly distinguishes community development, community organizing, service delivery, and advocacy. In this model, community development is the practice of "bricks and mortar" physical development. Community organizing is a confrontational social action form of community building where community members advocate for themselves. Advocacy is where professional activists advocate on behalf of a community, and service delivery is the typical form of social services.

In the Beckwith approach, which distinguishes sub-practices within the broader international definition field of community development, we can begin to think in more detailed ways about how Community Informatics can contribute. In such a model, Community Informatics becomes a support field. There are no longer Community Informatics projects, but community development projects that incorporate Community Informatics. In physical development projects, geographic information systems may be of use. In community organizing, e-mail communication or web-based target research could be incorporated. In advocacy and service delivery, electronic databases could be important. Community Informatics can study and develop catalogues of best practices for how information technology interfaces with those different activities. And it can provide technical assistance in implementing ICTs in specific development, organizing, service, and advocacy projects.

\section{Information Focus}

The only way to determine what information technologies are appropriate for a given community is to find out, first, about the community itself and, second, about the information the community is trying to get or use. So information has to be the second emphasis. It is appropriate that social informatics is associated not primarily with computer science but with library science, as it is in places like the Faculty of Information Studies at the University of Toronto. In such programs, a focus on information before technology has a fighting chance. Too much technology development comes out of the whims of those familiar with hardware and software and too little comes out of the needs of those familiar with information.

What does Community Informatics look like if it takes a community information approach? From a community development perspective, CI would look first at what information is needed to both understand 
a community and implement a particular development, organizing, service, and advocacy project. Is Geographic Information Systems mapping relevant to a particular project? Is a database of pending legislation useful? Is a survey of local housing conditions important? Is market research on possible new businesses required? And what forms of ICTs are needed for those - plotter printers, digital cameras, web survey applications, good walking shoes, or others?

A project-based research model (Stoecker, 2005) can help identify information needs. Project-based research is designed to follow community development project cycles, from the initial diagnosis of a community problem, to the prescription of what to do about that problem, to the actual implementation of the prescription, to the evaluation of the implementation. At each stage of the project cycle there are specific information needs. At the diagnosis stage, needs and asset assessments are common. At the prescription stage, policy research and best practices research are common. At the implementation stage, a wide variety of activities such as community theatre, target research, and other community events build out of a research foundation. And at the evaluation stage, of course, is the research attempting to find out how much change has been produced.

\section{Participatory Process}

Participation has become a crucial component of Community Informatics. The participatory design conference held in the United States every two years also focuses on how to integrate participatory processes with information and communication technologies. Participation is a common component in definitions of CI. One of the more interesting is Nancy Campbell and Virginia Eubanks' (n.d.) definition of Community Informatics as "a sustainable approach to community enrichment that integrates participatory design of information technology resources, popular education, and asset-based development to enhance citizen empowerment and quality of life." What interests me most about this definition is its emphasis on not just participatory design, but also on popular education, for the integration of popular education into Community Informatics is still relatively rare.

If you are not familiar with popular education, the practice is most associated with the Brazilian educator Paulo Freire, and in the United States with Myles Horton and the Highlander Research and Education Center (Horton and Freire, 1990). The practice is also growing in Australia through the Centre for Popular Education at the University of Technology at Sydney, among others. In brief, popular education emphasizes the people teaching themselves, rather than being told by outsiders what they should learn and how they should learn it. And that is a particularly challenging leap for those of us in Community Informatics to make. After all, computers are complicated things, and few of us can imagine a person who has never sat down in front of a computer being able to work it without us. But that is also what they said about politics, and popular educators have shown them to be wrong there. Yes, people do need training to get the most out of ICTs, but can they train each other, building the training curriculum out of their identified information needs, rather than having to submit to canned program classes?

What would Community Informatics look like if it were participatory in a popular education sense? First, the participation would occur in a community development context, as people studied their own community and began to identify local community development issues. Second, as part of this popular education process, people would identify a set of information issues - things they needed to know or information they needed to better manage - to support specific community development projects. Then, and only then, they could consider particular ICT applications that provided some potential for helping with those information issues.

\section{Community Informatics as Supporting Cast}

This empowerment model of Community Informatics has a number of implications for this emerging field. First, we need to subordinate our work to the broader work of community development, and we need to learn that literature and that theory. ICT is simply one category of tools for community development, just like housing, small business incubation, family support, and the wide array of other community development tools. As a consequence, Community Informatics becomes part of the supporting cast, not the lead player. In fact, the most important lesson we learned in building the CATNeT community networking project in Toledo was not how to develop small telecenters around the city, but how the process of developing those centers could build relationships among community members. 
Additionally, there remains a gap between those who are good at community development but not good at ICTs and those who are good at ICTs but not good at community development. There is a misperception in much of the field that it is the technology side that is really complicated, requiring a great deal of mystical expertise, while running a community meeting to plan a project requires no training at all. The reality is, in fact, quite the reverse. The reason so many Community Informatics projects operate with only small numbers of community participants is not that community members don't care about such projects, but that those of us organizing the projects are so bad at recruiting, involving, and empowering them. If you cannot get 100 people involved in a Community Informatics project then you probably need training in how to organize, involve, excite, and empower people.

It may seem like a pre-emptive diminution of this emerging field to assign it a supporting cast role. But it should not, because Community Informatics has had the good sense from its inception to concern itself not primarily with its own development, but with the development of communities around the globe. The ironic unintended consequence of that good sense, however, is that Community Informatics has paid too little attention to itself as an emerging field. Now is our opportunity to reflect on where we are, and how to play a conscious role in the transition to a community-centered world. 


\section{References}

Abrahamson, M. (1996). Urban enclaves : identity and place in America. New York: St. Martin's Press.

Beckwith, D, with C Lopez. (1997). Community organizing: people power from the grassroots. COMMORG: The on-line conference on community organizing and development. http://commorg.utoledo.edu/papers.htm. Accessed November 1, 2004.

Bieber, M., R. Civille, M. Gurstein and N. White. (2002). A white paper exploring research trends and issues in the emerging field of community informatics. http://www.is.njit.edu/vci/vci-whitepaper.doc. Accessed December 24, 2004.

Boothroyd, P., and H. C. Davis. (1993). Community economic development: three approaches. Journal of Planning Education and Research, 12, 230-240.

Boyte, H. (1984). Community is possible. New York: Harper and Row.

Campbell, N. D., and V. Eubanks. (n.d.) Community informatics as a pathway to social change. http://www.brillomag.net/COPC/CI/. Accessed November 1, 2004.

Castells, M. (1996). The rise of the network society. Cambridge, Mass., Blackwell.

--- (1997). The power of identity. Cambridge, Mass,, Blackwell.

---- (1998). End of millennium. Malden, Mass., Blackwell.

Community informatics and information systems: mapping the sector. (n.d.) http://www.communityinformatics.org/. Accessed November 1, 2004.

Community Informatics Research and Applications Unit (CIRA). (n.d.). About CIRA. http://cira.scm.tees.ac.uk/. Accessed November 1, 2004.

Cook, J. B., (1999). Community development theory. University of Missouri-Columbia Extension. http://muextension.missouri.edu/explore/miscpubs/mp0568.htm. Accessed November 1, 2004.

Day, P. (2000). Community Informatics: Participatory tools for social inclusion and active citizenship. Participatory Design Conference. City University of New York, Nov. 28-Dec. 1.

Denison, T., L. Stillman, G. Johanson, \& D. Schauder. (2003). Theory, practice, social capital, and information and communications technologies in Australia. http://www.ccnr.net/prato2003/papers/ccnrpaper.zip. Accessed November 1, 2004.

Duncan, O. D. (1959). Human ecology and population studies. Pages 678-716 in P.M. Hauser \& O.D. Duncan, (eds.) The study of population. Chicago: University of Chicago Press.

Duncan, O.D. (1961). From social system to ecosystem. Sociological Inquiry, 31, 140-149.

Hawley, A.H. (1973. Ecology and population. Science, 179: 1196-1201.

Evans, S. M., \& H. C. Boyte. (1986). Free spaces : the sources of democratic change in America. New York: Harper \& Row.

Gottdiener, M., \& J. Feagin. (1988). The paradigm shift in urban sociology. Urban Affairs Quarterly, 24, 163-187.

Gurstein, M. (ed.). (2000). Community Informatics: Enabling communities with information and communications technologies. Hershey, PA: Idea Group.

Gurstein, M. Community informatics. (2003). http://www.communities.org.ru/ci-text/ci-v2.doc. Accessed November 1, 2004.

Gurstein, M. (2003b). Effective use: A community informatics strategy beyond the digital divide. First Monday, 8(12). http://firstmonday.org/issues/issue8 12/gurstein/index.html. Accessed November 1,2004 
Harvey, D. (1985). The urbanization of capital : studies in the history and theory of capitalist urbanization. Baltimore, MD: Johns Hopkins University Press.

Horton, M., \& P. Freire. (1990). We Make the Road by Walking: Conversations on Education and Social Change. B. Bell, J. Gaventa, \&d J. Peters (eds). Philadelphia: Temple University Press.

Kling, R. (1999). What is social informatics and why does it matter? D-Lib Magazine, 5(1). http://www.dlib.org/dlib/january99/kling/01kling.html. Accessed November 1, 2004.

Logan, J. R., \& H. L. Molotch. (1987). Urban fortunes: The political economy of place. Berkeley: University of California Press.

Lyon, L. (1987). The community in urban society. Philadelphia: Temple University Press.

McIver, W. Jr. (n.d.). A community informatics for the information society. UNRISD briefing paper. http://www.ssrc.org/programs/itic/publications/civsocandgov/mciver.pdf. Accessed November 1, 2004.

McCusker, P., \& K. O'Dubhchair. (1999). Community Informatics - Defining an ethical framework. Presented at Ethicomp99 International Conference on the Social and Ethical Impacts of Information and Communication Technologies. Rome, Italy.

Medoff, P. \& H. Sklar. (1994). Streets of hope: The fall and rise of an urban neighborhood. Boston: South End Press.

Michel, H., A. Dickie, \& C. Hollstedt. (2002). Natural resource information needs of Aboriginal communities in the Southern Interior of British Columbia. British Columbia Journal of Ecosystems and Management, 2(1). http://www.forrex.org/publications/jem/2002/vol2/no1/art3_rev1.pdf. Accessed November 1, 2004.

O'Neil, D. (2001). Merging theory with practice: Toward an evaluation framework for Community Informatics. Paper presented at Internet Research 2.0: INTERconnections. October 10-14, University of Minnesota.

Penuel, B. (2001). The organization of learning in community technology centers. http://www.sri.com/policy/ctl/assets/pdfs/vstaera2001.pdf. Accessed November 1, 2004.

Pitkin, B. (2001). Community Informatics, hope or hype? http://csdl.computer.org/comp/proceedings/hicss/2001/0981/08/09818005.pdf. Accessed November 1, 2004.

Cloward, R. \& F. F. Piven. (1993). Regulating the poor: The functions of public welfare. New York: Vintage Press.

Robinson, S. (n.d.). Cybercafés and national elites: constraints on community networking in Latin America. http://www.ssrc.org/programs/itic/publications/civsocandgov/robinson2.pdf. Accessed November 1, 2004.

Russian Communities Online. (n.d.). Definition of community networking. http://www.communities.org.ru/definition.htm. Accessed November 1, 2004.

Ryan. W. (1976). Blaming the victim. New York: Vintage Books.

Stoecker, Randy. (2005). Research methods for community change: A project-based approach. Thousand Oaks, CA: Sage Publications.

----. (2004). The mystery of the missing social capital and the ghost of social structure: Why community development can't win. In R. Silverman (ed.) Community-Based Organizations in Contemporary Urban Society: The Intersection of Social Capital and Local Context. Detroit: Wayne State University Press. 
----. (2002). Toward a people's technology. Keynote address delivered to the "Community and Information Technology: the Big Questions" search conference, Monash University, Melbourne, Australia. http://www.ccnr.net/searchconf/stoecker.htm. Accessed November 1, 2004.

----. (2002b). Cyberspace vs. Face to face: Community Organizing in the New Millennium. Perspectives on Global Development and Technology. 1:143-164.

Strand, K., S. Marullo, N. Cutforth, R. Stoecker, \& P. Donohue. (2003). Community-Based Research in Higher Education: Methods, Models and Practice. San Francisco: Jossey-Bass.

Tamas, An., Y. Whitehorse \& O. Almonte. (2000). System theory in community development. http://www.tamas.com/samples/source\%2520docs/System\%2520Theory\%2520in\%2520CD.pdf. Accessed November 1, 2004.

Youth Development Trust for the IDRC, (2003). The impact of information and communications technology training on youth entrepreneurship and job creation. http://web.idrc.ca/uploads/userS/10566354940YDT_Final_Report21.doc. Accessed November 1, 2004. 